\title{
Antileishmanial activity and immunomodulatory effect of secosubamolide, a butanolide isolated from Nectandra oppositifolia (Lauraceae)
}

\author{
Thais A. da Costa-Silva ${ }^{1}$, Geanne A. Alves Conserva ${ }^{1}$, Andrés J. Galisteo Jr ${ }^{2}$, Andre G. Tempone ${ }^{3}$, \\ João Henrique G. Lago ${ }^{1, *}$ \\ ${ }^{1}$ Center of Natural Sciences and Humanities, Federal University of ABC (UFBAC), São Paulo, SP, Brazil. \\ ${ }^{2}$ Institute of Tropical Medicine, University of São Paulo (USP), São Paulo, SP, Brazil. \\ ${ }^{3}$ Centre for Parasitology and Mycology, Adolfo Lutz Institute (IAL), São Paulo, SP, Brazil.
}

\section{Keywords:}

Leishmania (L.) infantum chagasi

Antileishmanial

Nectandra oppositifolia

Secosubamolide

Immunomodulatory

\begin{abstract}
Background: Visceral leishmaniasis is a complex neglected tropical disease caused by Leishmania donovani complex. Its current treatment reveals strong limitations, especially high toxicity. In this context, natural products are important sources of new drug alternatives for VL therapy. Therefore, the antileishmanial and immunomodulatory activity of compounds isolated from Nectandra oppositifolia (Lauraceae) was investigated herein.
\end{abstract}

Methods: The $n$-hexane extract from twigs of N. oppositifolia were subjected to HPLC/ HRESIMS and bioactivity-guided fractionation to afford compounds $\mathbf{1}$ and $\mathbf{2}$ which were evaluated in vitro against Leishmania (L.) infantum chagasi and NCTC cells.

Results: The $n$-hexane extract displayed activity against $L$. (L.) infantum chagasi and afforded isolinderanolide $\mathrm{E}(\mathbf{1})$ and secosubamolide A (2), which were effective against $L$. (L.) infantum chagasi promastigotes, with $\mathrm{IC}_{50}$ values of 57.9 and $24.9 \mu \mathrm{M}$, respectively. Compound 2 was effective against amastigotes $\left(\mathrm{IC}_{50}=10.5 \mu \mathrm{M}\right)$ and displayed moderate mammalian cytotoxicity $\left(\mathrm{CC}_{50}=42 \mu \mathrm{M}\right)$. The immunomodulatory studies of compound 2 suggested an anti-inflammatory activity, with suppression of IL-6, IL-10, TNF with lack of nitric oxide.

Conclusion: This study showed the antileishmanial activity of compounds $\mathbf{1}$ and $\mathbf{2}$ isolated from N. oppositifolia. Furthermore, compound $\mathbf{2}$ demonstrated an antileishmanial activity towards amastigotes associated to an immunomodulatory effect.

\footnotetext{
* Correspondence: joao.lago@ufabc.edu.br http://dx.doi.org/10.1590/1678-9199-JVATITD-2019-0008 Received: 07 February 2019; Accepted: 27 June 2019; Published online: 19 August 2019
} 


\section{Background}

Visceral leishmaniasis (VL) is a complex neglected tropical disease caused by two species of Leishmania parasites: Leishmania (L.) infantum chagasi and Leishmania (L.) donovani. In South and Central Americas, Mediterranean Basin, Middle East and Central Asia, the VL agent is $L$. (L.) infantum chagasi while in Africa and Asia the agent is $L$. (L.) donovani $[1,2]$. According to Drug for Neglected Disease initiative (DNDi) annually there are 20.000 to 30.000 deaths attributed visceral leishmaniasis [3]. It is considered a prioritized infectious disease by the World Health Organization (WHO) due to the worldwide prevalence [1].

Leishmania parasites have elaborated escape mechanisms of immune response $[4,5]$. L. (L.) infantum chagasi invades cells of the mononuclear phagocytic system; reach mainly macrophages of spleen, liver and bone marrow and causes irregular fever, anemia, hepatosplenomegaly, pancytopenia, weight loss, and hypergammaglobulinemia [6]. Nowadays there are limited options of therapy for the various forms of leishmaniasis. The available treatment is based on the application of pentavalent antimonials (sodium stibogluconate and meglumine antimoniate), drugs that have been used for more than seven decades [2, 7]. This therapy shows a number of disadvantages for the patients, including high toxicity, adverse effects, requirement of hospitalization for the drug administration, and continuous increase of resistance that leads to decreasing effectiveness $[2,8,9]$. The single available drug for VL treatment by oral administration is the miltefosine, an anticancer drug. The antileishmanial effect was discovered in the 90's and in 2003 it was licensed for the treatment of VL [10]. Various antileishmanial mechanisms have been attributed to miltefosine: effects in the parasite membrane, mitochondrial alterations, and immunomodulatory action with Th1 response [11]. In this context, the search of new compounds against $L$. (L.) infantum chagasi that could elicit the host immune response could be an interesting strategy to kill the parasite inside the macrophages $[12,13]$. Natural products are an important source of new metabolites and play an important role in drug discovery and development process. Thus, these compounds could be considered a starting point for drug development due to their structural diversity and pharmacological potential [12-19].

In order to identify new antileishmanial molecules from Brazilian flora, the aim of this work was to investigate the in vitro antileishmanial activity of the $n$-hexane extract of the twigs of Nectandra oppositifolia ("canela-ferrugem" or "canela-amarela" in Portuguese). Nectrandra sp. is known for its anti-inflammatory, analgesic, and antiprotozoal [anti- $L$. (L.) donovani and anti-Trypanosoma cruzi] properties [19]. The genus Nectandra belongs to the Lauraceae family, which is composed of 2,500-3,000 species distributed in 49-50 genera. The distribution of this family occurs in tropical and subtropical regions of the world, predominantly in Southeast Asia and Brazil [20]. The studied extract was $100 \%$ active against promastigotes and amastigotes forms of $L$. (L.) infantum chagasi at the concentration of $200 \mu \mathrm{g} / \mathrm{mL}$, then it was subjected to HPLC/ HRESIMS analysis that indicated the predominance of two related metabolites: isolinderanolide E (1) and secosubamolide A (2). After purification over successive chromatographic steps, the effects of compounds 1 and 2 against $L$. (L.) infantum chagasi in macrophages and toxicity against mammalian cells were evaluated. Additionally, the immunomodulatory activity of active compound $\mathbf{2}$ was also assessed.

\section{Methods}

\section{General experimental procedures}

${ }^{1} \mathrm{H}$ and ${ }^{13} \mathrm{C}$ NMR spectra were registered at 500 and $125 \mathrm{MHz}$, respectively, on a Varian INOVA 500 spectrometer using $\mathrm{CDCl}_{3}$ as solvent and TMS as internal standards. Optical rotations were measured with a JASCO DIP-370 digital polarimeter. HPLC/ HRESIMS analysis was performed on a Thermo Scientific Dionex UltiMate DAD 3000 detector and a Phenomenex Luna C-18 column $(250 \times 4.6 \mathrm{~mm}, 5 \mu \mathrm{m})$ coupled on a Bruker Daltonics MicroTOF QII spectrometer using an Apollo ion source set as follows: dry temperature at $180^{\circ} \mathrm{C}$ and voltage at $4.5 \mathrm{kV}$. The mass/charge ratios were detected in scan $(m / z$ 100-1200 Da) and product ion scan $(m / z 50-1200 \mathrm{Da})$ modes. Chromatographic separation procedures were performed using $\mathrm{ACN}: \mathrm{H}_{2} \mathrm{O} 95: 5$ as eluent with a flow rate $1.0 \mathrm{~mL} / \mathrm{min}$ and detection at $235 \mathrm{~nm}$. For all extraction and chromatography procedures, were used analytical grade solvents.

\section{Plant material}

N. oppositifolia twigs were collected in the Atlantic Forest area of Arthur Nogueira city, São Paulo State (coordinates 22 $230^{\prime} 57,65^{\prime \prime}$ 'S, $47^{\circ} 10^{\prime} 50,11^{\prime \prime}$ W), Brazil, in April 2016. The plant material was identified by MSc. Guilherme M. Antar and a voucher specimen (SPF 225339) has been deposited in the Herbarium of Institute of Biosciences, University of São Paulo, SP, Brazil.

\section{Extraction}

N. oppositifolia twigs were dried, powdered $(310 \mathrm{~g})$ and exhaustively extracted using $n$-hexane at room temperature. After evaporation of the solvent at reduced pressure, $3.4 \mathrm{~g}$ of $n$-hexane extract were obtained.

\section{HPLC/HRESIMS analysis}

Part of crude $n$-hexane extract from twigs of N. oppositifolia (5 $\mathrm{mg}$ ) was dissolved in $1 \mathrm{~mL}$ of $\mathrm{MeOH}$ and filtered on a $\mathrm{C}_{18}$ SepPak. Sample containing $1 \mathrm{~mL}$ of crude extract was analyzed by HPLC/HRESIMS.

\section{Bioactivity-guided fractionation}

Part of the crude $n$-hexane extract $(3.0 \mathrm{~g})$ from twigs of $N$. oppositifolia was chromatographed over a silica gel column, eluted with increasing amounts of EtOAc in $n$-hexane. This procedure yielded 60 fractions ( $100 \mathrm{~mL}$ each) that were combined into five groups (A-E) on the basis of similarities on TLC profiles. As the activity against promastigote forms of $L$. (L.) 
infantum chagasi was detected in group C (277 mg), part of this bioactive group (245 mg) was chromatographed over a silica gel column, eluted with a mixture of $\mathrm{CHCl}_{3}: \mathrm{Me}_{2} \mathrm{CO} 96: 4(\mathrm{v} / \mathrm{v})$. This procedure resulted in eight groups (C1-C8) being activity against promastigote forms of $L$. (L.) infantum chagasi detected in groups C6 (54 mg) and C7 (32 mg). Part of group C6 (30 mg) was purified by RP-HPLC (eluent ACN: $\mathrm{H}_{2} \mathrm{O}$ 95:5) to afford pure compound 1 (6.0 mg). Part of bioactive group C7 (25 mg) was purified by silica gel prep. TLC $\left(\mathrm{CHCl}_{3}: \mathrm{Me}_{2} \mathrm{CO} 98: 2\right)$ to afford pure compound 2 (3.4 mg).

Isolinderanolide $E(\mathbf{1})$. White amorphous solid. $[\mathrm{a}]_{\mathrm{D}}{ }^{25}+13.8$ (c $\left.0.20, \mathrm{CHCl}_{3}\right) ;{ }^{1} \mathrm{H}$ NMR $\left(\mathrm{CDCl}_{3}, 500 \mathrm{MHz}\right) \mathrm{d} 7.09(1 \mathrm{H}, \mathrm{td}, J=$ 7.9 and $2.2 \mathrm{~Hz}, \mathrm{H}-6), 5.26(1 \mathrm{H}$, br s, H-3), $4.96(1 \mathrm{H}, \mathrm{dd}, J=2.8$ and $1.7 \mathrm{~Hz}, \mathrm{H}-5 \mathrm{a}), 4.73(1 \mathrm{H}, \mathrm{dd}, \mathrm{J}=2.8$ and $1.4 \mathrm{~Hz}, \mathrm{H}-5 \mathrm{~b}), 2.47$ (2H, m, H-7), 1.53 (2H, m, H-8), 1.26 (34H, s, H-9 to H-20), 0.88 $(3 \mathrm{H}, \mathrm{t}, J=6.9 \mathrm{~Hz}, \mathrm{H}-21) ;{ }^{13} \mathrm{C} \mathrm{NMR}\left(\mathrm{CDCl}_{3}, 125 \mathrm{MHz}\right) \mathrm{d} 166.5$ (C-1), 157.6 (C-4), 150.2 (C-6), 127.3 (C-2), 91.4 (C-5), 66.5 (C3), 31.9 (C-19), 29.7 - 29.4 (C-9 to C-19), 29.6 (C-7), 28.3 (C-8), 22.7 (C-20), 14.1 (C-21).

Secosubamolide $A$ (2). White amorphous solid. $[\mathrm{a}]_{\mathrm{D}}^{25}+18.1$ (c $\left.0.12, \mathrm{CHCl}_{3}\right) ;{ }^{1} \mathrm{H} \mathrm{NMR}\left(\mathrm{CDCl}_{3}, 500 \mathrm{MHz}\right) \mathrm{d} 7.08(1 \mathrm{H}, \mathrm{t}, J=$ $7.6 \mathrm{~Hz}, \mathrm{H}-6), 4.90$ (1H, br s, H-3), $3.73\left(3 \mathrm{H}, \mathrm{s}, 1-\mathrm{OCH}_{3}\right), 2.35$ $(2 \mathrm{H}, \mathrm{t}, J=7.6 \mathrm{~Hz}, \mathrm{H}-7), 2.15(3 \mathrm{H}, \mathrm{s}, \mathrm{H}-5), 1.53(2 \mathrm{H}, \mathrm{t}, J=7.6 \mathrm{~Hz}$, $\mathrm{H}-8), 1.31-1.25(34 \mathrm{H}, \mathrm{s}, \mathrm{H}-8$ to $\mathrm{H}-20), 0.88(3 \mathrm{H}, \mathrm{t}, J=7.0 \mathrm{~Hz}$, $\mathrm{H}-21) ;{ }^{13} \mathrm{C} \mathrm{NMR}\left(\mathrm{CDCl}_{3}, 125 \mathrm{MHz}\right) \mathrm{d} 206.3$ (C-4), 166.6 (C-1), 149.1 (C-6), 129.2 (C-2), 73.4 (C-3), 52.0 (1- $\left.\mathrm{OCH}_{3}\right), 31.9$ (C-19), 29.7 - 29.4 (C-9 to C-18), 28.9 (C-7), 28.7 (C-8), 24.8 (C-5), 22.7 (C-20), 14.1 (C-21).

\section{Experimental animals}

The experimental animals used in this study, golden hamsters (Mesocricetus auratus) and BALB/c mice, were supplied by the Instituto Adolfo Lutz of São Paulo State, Brazil. The animals received food and water ad libitum and maintained in sterile boxes. Golden hamsters were inoculated every month with amastigotes purified from spleen derived of a previously infected hamster, for the maintenance of the $L$. (L.) infantum chagasi strain. BALB/c mice were used as a source of peritoneal macrophages. Animal procedures were conducted with the approval of the Ethics Committee of Instituto Adolfo Lutz (project CEUA-IAL/Pasteur 05/2011) in accordance with the National Institutes of Health "Guide for the Care and Use of Laboratory Animals” (NIH Publications No. 8023).

\section{L. (L.) infantum chagasi promastigotes, peritoneal macrophages, and NCTC cell culture}

L. (L.) infantum chagasi parasites (MHOM/BR/1972/LD) were maintained through successive passages in golden hamsters up to 60-70 days after infection. The amount of parasites in the spleen was determined 60-70 days post infection [21]. Promastigotes forms were kept in cell culture flasks in M-199 medium supplemented with $10 \%$ fetal calf serum (FCS) and 0.25 $\%$ hemin at $24^{\circ} \mathrm{C}$ BOD incubator. Macrophages were obtained from the peritoneal cavity of BALB/c mice by washing with RPMI-1640 medium supplemented with 10\% FCS and kept at $37^{\circ} \mathrm{C}$ in a $5 \% \mathrm{CO}_{2}$-humidified incubator [22]. Murine fibroblasts NCTC cells (clone L929 ATCC) were kept in cell culture flasks in M-199 medium supplemented with $10 \% \mathrm{FBS}$ and $20 \mu \mathrm{g} / \mathrm{mL}$ gentamicin at $37^{\circ} \mathrm{C}$ in a $5 \% \mathrm{CO}_{2}$-humidified incubator.

\section{Evaluation of $\mathbf{5 0 \%}$ inhibitory concentration (IC ${ }_{50}$ ) against $L$. (L.) infantum chagasi and $50 \%$ cytotoxicity concentration $\left(\mathrm{CC}_{50}\right)$ against NCTC cells}

To determine the $\mathrm{IC}_{50}$ concentration against promastigotes forms of $L$. (L.) infantum chagasi the crude $n$-hexane extract from $N$. oppositifolia, fractions and compounds $\mathbf{1}$ and $\mathbf{2}$ were dissolved in DMSO and diluted in M-199 medium in 96-well microplates. Extract/fractions were tested at highest concentration of 200 $\mu \mathrm{g} / \mathrm{mL}$ while purified compounds were serially tested at the concentrations of 150 to $1.71 \mu \mathrm{M}$. The promastigotes (late growth phase) were counted in a Neubauer chamber and seeded at 1 x $10^{6} /$ well and incubated with the compounds in the different concentrations for $48 \mathrm{~h}$ at $24^{\circ} \mathrm{C}$ in a BOD incubator. The viability of the parasites was evaluated using the MTT reagent [23]. Miltefosine was used as standard drug. An internal control group was used with $0.5 \%$ DMSO (maximal concentration).

To determine the $\mathrm{CC}_{50}$ concentration, compounds $\mathbf{1}$ and $\mathbf{2}$ were dissolved and diluted as described above. Thus, compounds were serially tested at the concentrations of 200 to $1.56 \mu \mathrm{M}$. NCTC cells were scrapped from the cell culture flasks counted in a Neubauer chamber and seeded at $6 \times 10^{4}$ cells/well and incubated with compounds in the different concentrations for $48 \mathrm{~h}$ at $37^{\circ} \mathrm{C}$ in a $5 \% \mathrm{CO}_{2}$-humidified incubator. The viability of the cells was evaluated using the MTT reagent [23].

To determine the $\mathrm{IC}_{50}$ concentration against intracellular forms of $L$. (L.) infantum chagasi (amastigotes), macrophages collected from the peritoneal cavity of BALB/c mice were counted in a Neubauer chamber, seeded at $1 \times 10^{5} /$ well in a 16 -well slide and kept in a $5 \% \mathrm{CO}_{2}$-humidified incubator overnight. Posteriorly, amastigotes were collect from a previously infected hamster as described, seeded at a ratio 1:10 (macrophages:amastigotes) and maintained at $37^{\circ} \mathrm{C}$ in a $5 \% \mathrm{CO}_{2}$-humidified incubator for $24 \mathrm{~h}$. Subsequently, crude extract and fractions were incubated with the infected macrophages to the highest concentration of 200 $\mu \mathrm{g} / \mathrm{mL}$ while pure compounds 1 and 2 were tested at range 100 to $1.56 \mu \mathrm{M}$ with infected macrophages for $96 \mathrm{~h}$. Miltefosine was used as a standard drug. Last step of the assay, the macrophages were fixed with $\mathrm{MeOH}$, stained with Giemsa (Merck KGaA, Germany), and analyzed on a light microscope. The parasite burden was determined by the number of infected macrophages out of 200 cells.

\section{Quantification of cytokine production by macrophages}

Peritoneal macrophages from a BALB/c mice were counted in a Neubauer chamber and seeded in 24 -well plates at $1 \times 10^{5}$ 
cells/well in RPMI medium supplemented with 10\% FBS and incubated for $24 \mathrm{~h}$ at $37^{\circ} \mathrm{C}$ in a $5 \% \mathrm{CO}_{2}$-humidified incubator. Next, the macrophages were washed with PBS and infected (overnight) with $L$. (L.) infantum chagasi amastigotes (ratio 10:1). Subsequently, cells were washed with PBS and treated with compound 2 (at $\mathrm{IC}_{50}$ value) for $48 \mathrm{~h}$. Lipopolysaccharides (LPS) from Escherichia coli (Sigma-Aldrich, USA) was used as a positive control of production of cytokines. Non-infected macrophages were also treated with compound $\mathbf{2}$ in order to compare them with the treatment for infected cells. The cytokines levels were analyzed in culture supernatants after $48 \mathrm{~h}$ post treatment. The concentration of interleukin-6 (IL-6), interleukin-10 (IL-10), monocyte chemoattractant protein-1 (MCP-1) and tumor necrosis factor (TNF) was determined using an inflammatory CBA kit assay (BD Mouse Inflammation Kit, USA) in accordance with manufacturer protocols by flow cytometry (BD-LSR FORTESSA).

\section{Quantification of nitric oxide (NO)}

To determine the NO concentration, peritoneal macrophages collected as described above were treated with compound 2 for $48 \mathrm{~h}$ at $\mathrm{IC}_{50}$ concentrations. The quantification of NO was determined by the Griess assay [24] in the supernatants of treated cells. LPS from Escherichia coli (Sigma-Aldrich, USA) was used as a positive control of production of NO. Obtained data were calculated from a standard curve prepared with $\mathrm{NaNO}_{2}$ in concentrations ranging from 1 to $400 \mu \mathrm{M}$.

\section{Statistical Analysis}

The results were reported as the mean and standard deviation of duplicate samples from two or three independent assays. $\mathrm{IC}_{50}$ and $\mathrm{CC}_{50}$ values were calculated using sigmoid dose-response curves in Graph Pad Prism 5.0 software (Graph Pad Software, USA), ANOVA for significance ( $\mathrm{p}<0.05)$.

\section{Results and Discussion}

The parasitic activity of the $n$-hexane extract of the twigs of $N$. oppositifolia was determined against $L$. (L.) infantum chagasi (promastigote and amastigote forms), causing $100 \%$ of parasite death at $200 \mu \mathrm{g} / \mathrm{mL}$. Aiming at the identification of bioactive compounds, the crude extract was analyzed by HPLC/HRESIMS and two main peaks were detected (Figure 1). Mass spectra analysis suggested the occurrence of two related butanolides due to the quasi-molecular ion peaks at $m / z 337.2771[\mathrm{M}+\mathrm{H}]^{+}$ and $391.2808[\mathrm{M}+\mathrm{Na}]^{+}$, corresponding to molecular formulas $\mathrm{C}_{21} \mathrm{H}_{36} \mathrm{O}_{3}$ (compound 1) and $\mathrm{C}_{22} \mathrm{H}_{40} \mathrm{O}_{4}$ (compound 2), respectively. After successive chromatographic steps, compounds $\mathbf{1}$ and 2 were isolated in $99 \%$ of purity as indicated by HPLC. Structures of isolinderanolide $\mathrm{E}$ and secosubamolide A (Figure 2) were confirmed by analysis of ${ }^{1} \mathrm{H}$ and ${ }^{13} \mathrm{CNMR}$ spectra and comparison with data reported in the literature $[25,26]$.

In vitro antileishmanial activity of the isolated butenolides against the promastigotes and amastigotes forms of the $L$. $(L$. infantum chagasi and mammalian cytotoxicity (NCTC cells)

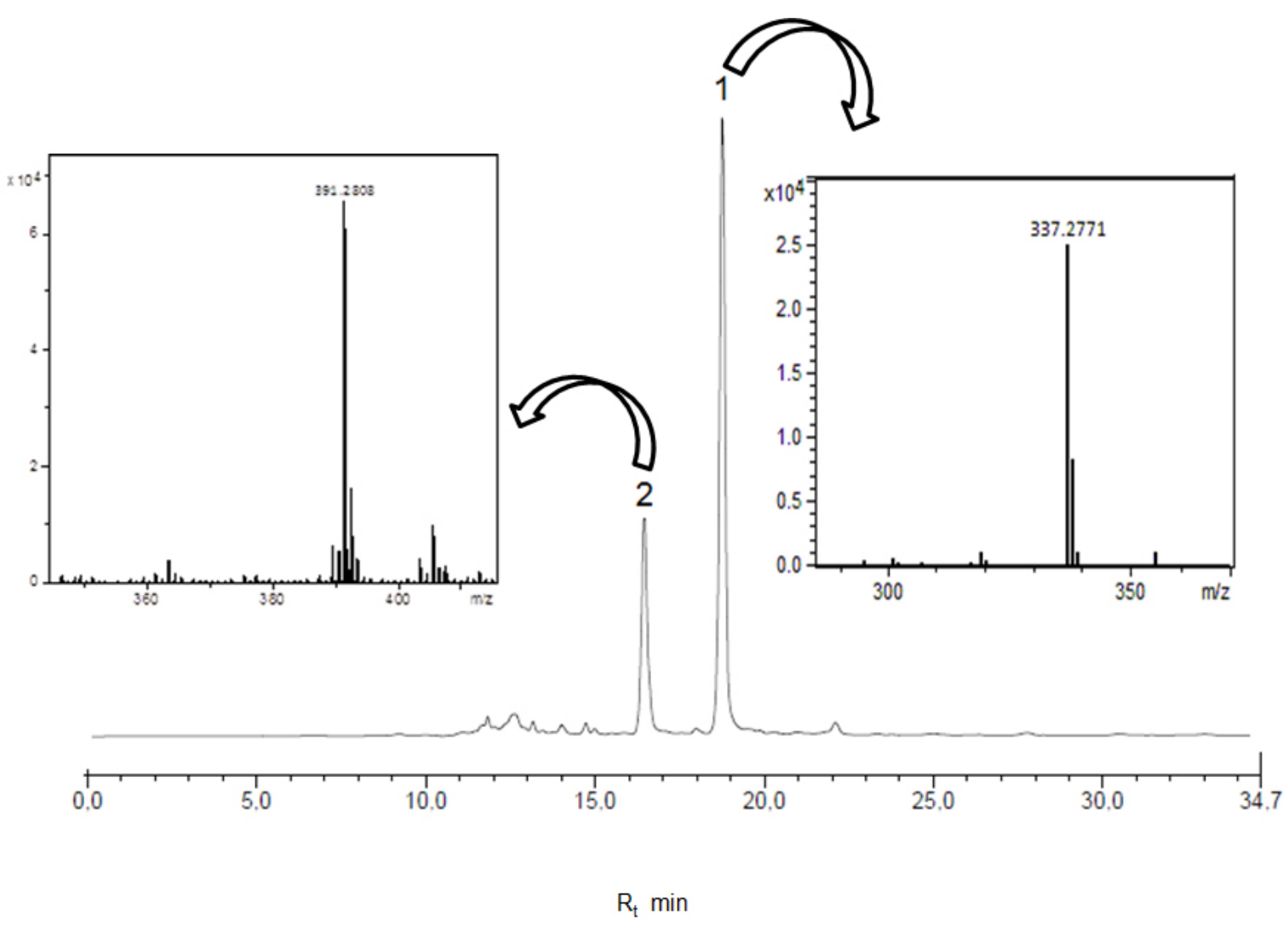

Figure 1. HPLC/HRESIMS analysis of crude $n$-hexane extract from twigs of $N$. oppositifolia. 
were evaluated. Butanolides $\mathbf{1}$ and $\mathbf{2}$ were effective against L. (L.) infantum chagasi promastigotes, with $\mathrm{IC}_{50}$ values of $57.9 \pm 15.4$ and $24.9 \pm 2.8 \mu \mathrm{M}$. Considering the effect against amastigotes, compound 2 was effective with an $\mathrm{IC}_{50}$ value of $10.5 \pm 2.3 \mu \mathrm{M}$. Compound 2 was more toxic than the standard drug (miltefosine) and it was specifically more effective against intracellular amastigote forms of the parasite (Table 1). As previously reported [27], lactones with an aliphatic side chain displayed activity and reduced cytotoxicity against amastigote forms of Leishmania sp. Another important structural aspect of this activity is the presence of the $\mathrm{a}, \mathrm{b}$-unsaturated lactone moiety since saturated derivatives showed reduced activity [28]. Our results indicated that despite compound 1 exhibit these structural characteristics described above, it was active only against the extracellular promastigotes. Otherwise, it is biosynthetically related to compound 2 , which showed an opening lactone unity, but maintaining the a,b-unsaturated system. Compound $\mathbf{2}$ showed activity against the extracellular (promastigote) and intracellular (amastigote) forms of $L$. (L.) infantum chagasi. Therefore, this is an important structural aspect to be considered for the future synthesis of new related bioactive derivatives.

Considering the activity of the compound $\mathbf{2}$ against the amastigotes inside macrophages, the immunomodulatory effect in Leishmania-infected cells was also evaluated. The mechanism of cellular death of intracellular amastigotes of Leishmania could be an event associated to the activation of microbicide mechanisms of the macrophages, particularly the increasing of production of NO levels [29]. Different natural products such as sesquiterpene lactones, alkaloids and neolignans demonstrated this effect $[13,30,31]$. Compound 2 showed no induction of NO production in macrophages (data not shown). Furthermore, the analysis of the cytokine profile of infected and non-infected macrophages after treatment with compound 2 demonstrated an anti-inflammatory profile (Figure 3). This compound negatively modulated the production of one of the cytokine that is related to disease progression, IL-6, in infected and non-infected macrophages [12,32, 33]. Moreover, this compound did not increment IL-10 in statistically significant levels in infected macrophages, which favors treatment, since IL-10 is also related
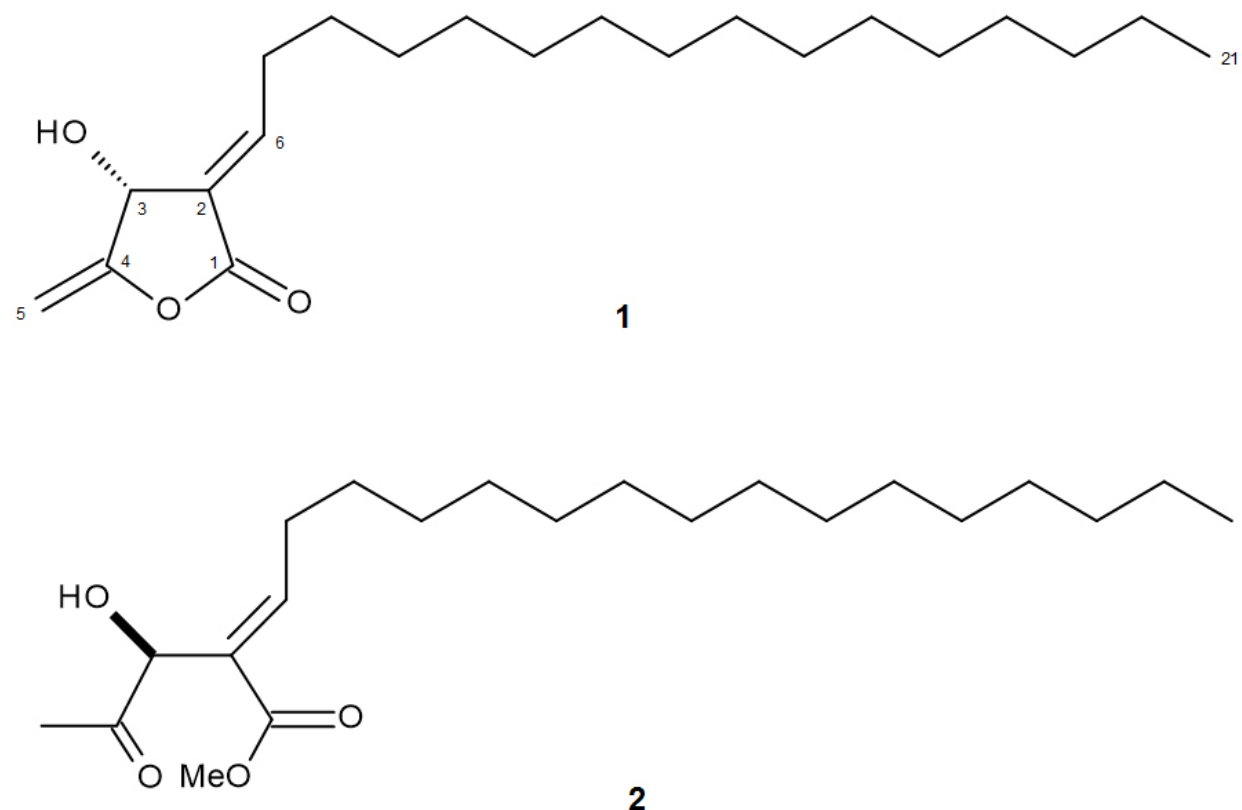

Figure 2. Structures of compounds $\mathbf{1}$ and $\mathbf{2}$ isolated from twigs of N. oppositifolia.

Table 1. Antileishmanial activity (promastigote and amastigote forms) and mammalian cytotoxicity (NCTC cells) of compounds $\mathbf{1}$ and $\mathbf{2}$, isolated from N. oppositifolia

\begin{tabular}{|c|c|c|c|c|}
\hline \multirow{3}{*}{ Compounds } & \multicolumn{2}{|c|}{ L. (L.) infantum chagasi } & \multirow{3}{*}{$\begin{array}{c}\text { NCTC } \\
\text { CC }_{50}{ }^{b} \mu M \\
(95 \% \mathrm{CI})\end{array}$} & $\mathbf{S \mathbf { I } ^ { \mathrm { c } }}$ \\
\hline & \multicolumn{2}{|c|}{$\mathrm{IC}_{50}{ }^{\mathrm{a}} \mu \mathrm{M}(95 \% \mathrm{CI})$} & & \multirow{2}{*}{ Amastigote } \\
\hline & Amastigote & Promastigote & & \\
\hline 2 & $10.5 \pm 2.3$ & $24.9 \pm 2.8$ & $42.3 \pm 14.8$ & 4.0 \\
\hline Miltefosine & $17.8 \pm 1.4$ & $16.7 \pm 3.5$ & $>200$ & $>11.2$ \\
\hline
\end{tabular}

a: 50\% inhibitory concentration, b: 50\% cytotoxic concentration, c: Selectivity Index in intracellular amastigote forms; $95 \%$ CI: $95 \%$ confidence interval; NA: non active. 
to VL progression [33-35,]. In addition, compound 2 increased the production of MCP-1 (CCL-2). CCL-2 is an important chemokine associated with the reduction of the parasite load and granuloma formation in the liver in experimental model of VL [36-39], with no interference in TNF levels, which could be related to the absence of NO. Higher levels of TNF are involved in macrophage activation and upregulation of iNOS expression, leading to the upregulation of NO levels [36]. Then, a possible antileishmanial effect of secosubamolide A may involve the suppression of IL- 6 and increase of MCP-1.

\section{Conclusion}

This work showed, for the first time in the literature, the antiLeishmania (L.) infantum chagasi activity of related butanolide isolinderanolide $\mathrm{E}$ (1) and secosubamolide A (2) isolated from N. oppositifolia. Furthermore, compound $\mathbf{2}$ demonstrated an anti-L. (L.) infantum chagasi activity towards the most relevant parasite form, associated to an immunomodulatory effect in the host cells. The moderate selectivity found for this compound could be further improved in drug design studies.

\section{Acknowledgments}

The authors would like to thank UFABC, USP, IAL, São Paulo State Research Foundation (FAPESP), Coordination for the Improvement of Higher Education Personnel (CAPES), and National Council for Scientific and Technological Development (CNPq) for their support.

\section{Abbreviations}

$\mathrm{CC}_{50}: 50 \%$ cytotoxicity concentration; DNDi: Drug for Neglected Disease initiative; FCS: fetal calf serum; $\mathrm{IC}_{50}: 50 \%$ inhibitory concentration; IL-10: interleukin-10; IL-6: interleukin-6; LPS: lipopolysaccharides; MCP-1: monocyte chemoattractant protein-1; NO: nitric oxide; TNF: tumor necrosis factor; VL: visceral leishmaniasis.
IL-6

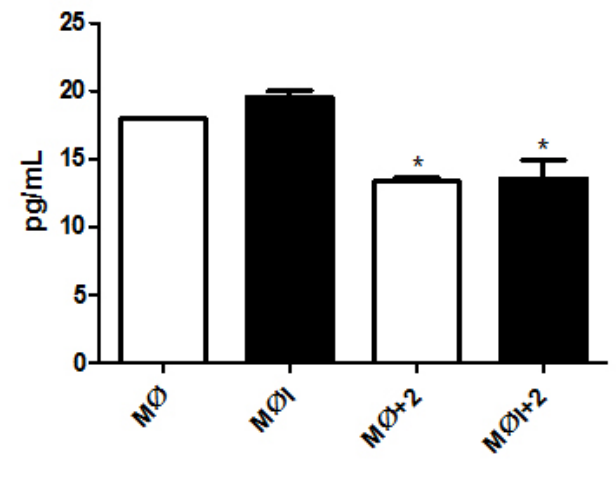

MCP-1

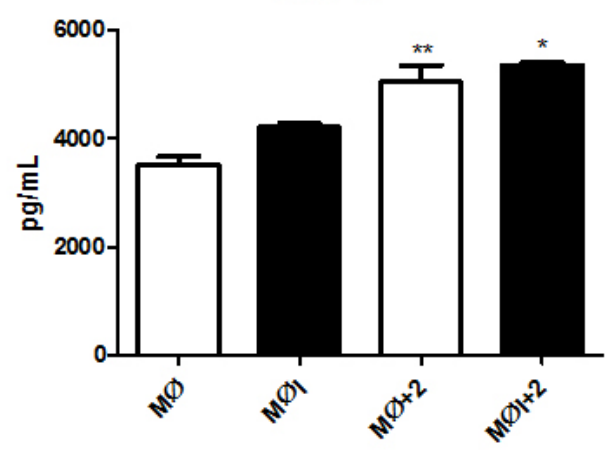

IL-10

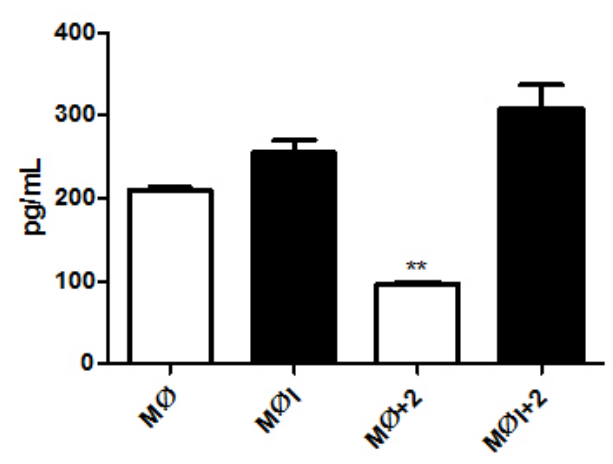

TNF

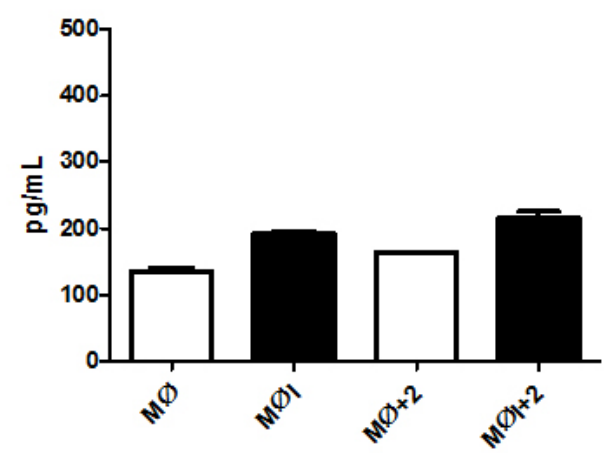

Figure 3. Effects of treatment of $L$. (L.) infantum chagasi-infected macrophages with secosubamolide $A$ (compound $\mathbf{2}$ ) on the production of proinflammatory cytokines (TNF, MCP-1, IL-6, and IL-10). LPS was used as positive control, and macrophages without treatment were used as negative control. The results are expressed in $\mathrm{pg} / \mathrm{mL}$, and the mediators were measured by flow cytometry (BD-LSR FORTESSA) in the culture supernatants with the CBA kit assay (BD Mouse Inflammation Kit, USA). MØ: macrophages, MØI: Leishmania-infected macrophages. (IL-6) LPS production: MØ 8737 pg/mL, MØI 9060 pg/mL. (IL-10) LPS production: MØ 859 pg/mL, MØI 955 pg/mL. (MCP-1) LPS production: MØ 4769 pg/mL, MØI 5301 pg/mL. (TNF) LPS production: MØ 4973 pg/mL, MØI 5260 pg/mL. 


\section{Availability of data and materials}

All data generated or analyzed during this study are included in this article

\section{Funding}

This study was supported by grants from FAPESP (2018/07885-1, 2018/10279-6 and 2016/20633-6). The authors also thank CAPES for the scholarships to TACS and CNPq for the grant awarded to JHGL and AGT. The publication of the present article was supported by Programa Editorial CNPq/CAPES (chamada $n$. 26/2017, processo n. 440954/2017-7).

\section{Competing interests}

The authors declare that they have no competing interests

\section{Authors' contributions}

TACS, GAAC and AJG performed the research and analyzed data. AGT, TACS and JHGL wrote the manuscript. AGT and JHGL designed the study. All authors read and approved the final manuscript.

\section{Ethics approval}

The animal assays were performed with the approval of the Research Ethics Commission (CEUA 05/2011), in agreement with the "Guide for the Care and Use of Laboratory Animals" of the National Institutes of Health.

\section{Consent for publication}

Not applicable.

\section{References}

1. World Health Organization - Leishmaniasis. Fact. sheet. http://www. who.int/mediacentre/factsheets/fs375/en/. WHO. Accessed 03 Feb 2019.

2. Burza S, Croft SL, Boelaert M. Leishmaniasis. Lancet. 2018;392:951-70.

3. Drugs for Neglected Diseases Iniciative. https://www.dndi.org/diseasesprojects/leishmaniasis/. DNDi. Accessed 04 Feb 2019.

4. Real F, Florentino PT, Reis LC, Ramos-Sanchez EM, Veras PS, Goto H, et al. Cell-to-cell transfer of Leishmania amazonensis amastigotes is mediated by immunomodulatory LAMP-rich parasitophorous extrusions. Cell Microbiol. 2014;16(10):1549-64.

5. Srivastava A, Singh N, Mishra M, Kumar V, Gour JK, Bajpai S, et al. Identification of TLR inducing Th1-responsive Leishmania donovani amastigote-specific antigens. Mol Cell Biochem. 2012;359(1-2):359-68.

6. de Freitas EO, Leoratti FMS, Freire-de-Lima CG, Morrot A, Feijó DF. The contribution of immune evasive mechanisms to parasite persistence in visceral leishmaniasis. Front Immunol. 2016;7:153.

7. Tiuman TS, Santos AO, Ueda-Nakamura T, Filho BP, Nakamura CV. Recent advances in leishmaniasis treatment. Int J Infect Dis. 2011;15(8):e525-32.

8. McGwire BS, Satoskar AR. Leishmaniasis: clinical syndromes and treatment. QJM. 2014;107(1):7-14.

9. Sundar S, Chakravarty J. Antimony toxicity. Int J Environ Res Public Health. 2010;7(12):4267-77.

10. Croft SL, Engel J. Miltefosine--discovery of the antileishmanial activity of phospholipid derivatives. Trans R Soc Trop Med Hyg. 2006;100(Suppl 1):S4-8.
11. Palic S, Bhairosing P, Beijnen JH, Dorlo TPC. Host-mediated activity of miltefosine in leishmaniasis through immunomodulation: a systematic review. Antimicrob Agents Chemother. 2019:pii: AAC.02507-18.

12. da Costa-Silva TA, Grecco SS, de Sousa FS, Lago JH, Martins EG, Terrazas CA, et al. Immunomodulatory and antileishmanial activity of phenylpropanoid dimers isolated from Nectandra leucantha. J Nat Prod. 2015;78(4):653-7.

13. Wulsten IF, Costa-Silva TA, Mesquita JT, Lima ML, Galuppo MK, Taniwaki NN, et al. Investigation of the anti-Leishmania (Leishmania) infantum activity of some natural sesquiterpene lactones. Molecules. 2017;22(5):pii: E685.

14. Tempone AG, Martins de Oliveira C, Berlinck RG. Current approaches to discover marine antileishmanial natural products. Planta Med. 2011;77(6):572-85.

15. Sen R, Chatterjee M. Plant derived therapeutics for the treatment of Leishmaniasis. Phytomedicine. 2011;18(12):1056-69.

16. Schmidt TJ, Khalid SA, Romanha AJ, Alves TM, Biavatti MW, Brun R, et al. The potential of secondary metabolites from plants as drugs or leads against protozoan neglected diseases - part I. Curr Med Chem. 2012;19(14):2128-75.

17. Schmidt TJ, Khalid SA, Romanha AJ, Alves TM, Biavatti MW, Brun R, et al. The potential of secondary metabolites from plants as drugs or leads against protozoan neglected diseases - part II. Curr Med Chem. 2012;19(14):2176-228.

18. Newman DJ, Cragg GM. Natural products as sources of new drugs from 1981 to 2014. J Nat Prod. 2016;79(3):629-61.

19. Grecco SS, Lorenzi H, Tempone AG, Lago JHG. Update: biological and chemical aspects of Nectandra genus (Lauraceae). Tetrahedron: Asymmetry. 2016;27(17-18):793-810.

20. Cronquist A. An Integrated System of Classification of Flowering Plants (The New York Botanical Garden ed.). New York: Columbia University Press; 1992.

21. Stauber LA, Franchino EM, Grun J. An eight-day method for screening compounds against Leishmania donovani in the golden hamster. J Protozool. 1958;5(4):269-73.

22. Ueno AK, Barcellos AF, Costa-Silva TA, Mesquita JT, Ferreira DD, Tempone AG, et al. Antitrypanosomal activity and evaluation of the mechanism of action of diterpenes from aerial parts of Baccharis retusa (Asteraceae). Fitoterapia. 2018;125:55-8.

23. Tada H, Shiho O, Kuroshima K, Koyama M, Tsukamoto K. An improved colorimetric assay for interleukin 2. J Immunol Methods. 1986;93(2):157-65.

24. Lezama-Dávila CM, Isaac-Márquez AP, Barbi J, Cummings HE, Lu B, Satoskar AR. Role of phosphatidylinositol-3-kinase-gamma (PI3Kgamma)mediated pathway in 17 beta-estradiol-induced killing of $L$. mexicana in macrophages from C57BL/6 mice. Immunol Cell Biol. 2008;86(6):539-43.

25. Seki K, Sasaki T, Wano S, Haga K, Kaneko R. Linderanolides and isolideranolides, ten butanolides from Lindera glauca. Phytochemistry. 1995;40:1175-81.

26. Kuo SY, Hsieh TJ, Wang YD, Lo WL, Hsui YR, Chen CY. Cytotoxic constituents from the leaves of Cinnamomum subavenium. Chem Pharm Bull (Tokyo). 2008;56(1):97-101.

27. Castaño M, Cardona W, Quiñones W, Robledo S, Echeverri F. Leishmanicidal activity of aliphatic and aromatic lactones: correlation structure-activity. Molecules. 2009;14(7):2491-5001.

28. Cardona W, Quinones W, Robledo S, Vélez ID, Murga J, Garcla-Fortanet J, et al. Antiparasite and antimycobacterial activity of passifloricin analogues. Tetrahedron. 2006;62(17):4086-92.

29. Muller I, Pedrazzini T, Farrell JP, Louis J. T-cell responses and immunity to experimental infection with Leishmania major. Annu Rev Immunol. 1989;7:561-78.

30. Sharma M, Chauhan K, Shivahare R, Vishwakarma P, Suthar MK, Sharma A, et al. Discovery of a new class of natural product-inspired quinazolinone hybrid as potent antileishmanial agents. J Med Chem. 2013;56(11):4374-92.

31. Di Giorgio C, Lamidi M, Delmas F, Balansard G, Ollivier E. Antileishmanial activity of quinovic acid glycosides and cadambine acid isolated from Nauclea diderrichii. Planta Med. 2006;72(15):1396-402. 
32. Murray HW. Accelerated control of visceral Leishmania donovani infection in interleukin-6 deficient mice. Infect Immun. 2008;76(9):4088-91.

33. Ansari NA, Saluja S, Salotra P. Elevated levels of interferon-gamma, interleukin-10, and interleukin-6 during active disease in Indian kala azar. Clin Immunol. 2006;119(3):339-45.

34. Verma S, Kumar R, Katara GK, Singh LC, Negi NS, Ramesh V, et al. Quantification of parasite load in clinical samples of leishmaniasis patients: IL-10 level correlates with parasite load in visceral leishmaniasis. PLoS One. 2010;5(4):e10107.

35. Costa DL, Rocha RL, Carvalho RM, Lima-Neto AS, Harhay MO, Costa $\mathrm{CH}$, et al. Serum cytokines associated with severity and complications of kala-azar. Pathog Glob Health. 2013;107(2):78-87.
36. Dey R, Majumder N, Bhattacharyya Majumdar S, Bhattacharjee S, Banerjee $\mathrm{S}$, Roy S, et al. Induction of host protective Th1 immune response by chemokines in Leishmania donovani-infected BALB/c mice. Scand J Immunol. 2007; 66(6):671-83.

37. Cotterell SE, Engwerda CR, Kaye PM. Leishmania donovani infection initiates $\mathrm{T}$ cell-independent chemokine responses, which are subsequently amplified in a T cell-dependent manner. Eur J Immunol. 1999;29(1):203-14.

38. Kaye PM, Beattie L. Lessons from other diseases: granulomatous inflammation in leishmaniasis. Semin Immunopathol. 2016;38(2):249-60.

39. Bronte $\mathrm{V}$, Zanovello P. Regulation of immune responses by L-arginine metabolism. Nat Rev Immunol. 2005;5(8):641-54. 